\title{
Uma análise das seleções da Copa do Mundo de Futebol 2018 utilizando uma rede de transferências de jogadores entre países
}

\section{Title: Evaluation of teams in FIFA World Cup using a network of players transfers}

\author{
Lucas G. S. Félix ${ }^{2}$, Carlos M. Barbosa ${ }^{1}$, Iago A. Carvalho ${ }^{2}$, \\ Vinícius da F. Vieira ${ }^{1}$, Carolina Ribeiro Xavier $^{1}$ \\ ${ }^{1}$ Departamento de Ciência da Computação - Universidade Federal de São João del-Rei \\ Av. Visconde do Rio Preto S/N - Colônia do Bengo \\ ${ }^{2}$ Departamento de Ciência da Computação - Universidade Federal de Minas Gerais \\ \{lucasgsfelix, cmagnobarbosa\}@gmail.com, iagoac@dcc.ufmg.br \\ \{carolinaxavier, vinicius\}@ufsj.edu.br
}

\begin{abstract}
Football is the most popular sport in the world. The growth in the number of transactions of purchase and sale, marketing, sponsorships, sale of tickets, TV contracts, among other forms of monetization of football makes the flow of values increasingly higher. The majority of works related to this sport is associated with sociological analysis. This work proposes a study focused on the transactions occurred among the football teams classified to the World Cup 2018 using complex networks techniques for an analysis of the transfer of players among these countries. Also was also realized a analysis of the best placed countries in the World Cup, France, Croatia, Belgium and England. Through our analysis was possible to notice that the main countries in the generated rankings are European countries. Besides that, using community detection algorithms was possible to note that countries in the same cluster tend to be commercial partners.
\end{abstract}

Resumo. O futebol é o esporte mais popular do mundo. O crescimento no número de transações de compra e venda de jogadores, marketing, patrocínios, venda de ingressos, contratos de TV, entre outras formas de monetização do futebol faz com que o fluxo de valores seja cada vez maior. Grande parte dos trabalhos relacionados a esse esporte são associados a análises sociológicas. Neste trabalho, é proposto um estudo focado nas transações feitas entre as seleções classificadas para a Copa do Mundo 2018 utilizando técnicas de redes complexas para uma análise da transferência de jogadores entre esses países. Também foi realizada uma análise com os países que ficaram melhores colocados nesta edição do evento, sendo eles França, Croácia, Bélgica e Inglaterra. Por meio das análises realizadas foi possível perceber que os principais rankings de importância gerados são dominados por países europeus. Além disso, 
por meio da utilização de algoritmos de detecção de comunidades foi possível notar que países que estão presentes em um mesmo cluster tendem a ser parceiros comerciais.

\section{Introdução}

O futebol é atualmente o esporte mais popular do mundo [Palacios-Huerta 2004, Liebig et al. 2012]. O esporte possui milhares de praticantes e atrai bilhões de espectadores tanto para campeonatos locais e regionais, como para nacionais, continentais e mundiais. A partir disso, os clubes de futebol geram um enorme fluxo financeiro através da venda de ingressos e jogadores, contratos de televisão, marketing e merchandising, entre outros. Atualmente, o maior mercado comercial para o futebol é a Inglaterra, cujo mercado movimentou aproximadamente 1.3 bilhões de euros apenas na temporada 2016/2017 [Deloitte 2016].

Dentre as diversas formas de arrecadação financeira que um clube pode ter, destacam-se as transferências de jogadores entre clubes. Estes processos de compra e venda possibilitam que clubes arrecadem uma grande quantidade de dinheiro de forma rápida, vendendo seus melhores jogadores para outros clubes de maior poder aquisitivo. Estas transferências são catalogadas e classificadas no site Transfermarket ${ }^{1}$, que contém uma grande quantidade de dados em relação a transações de compra e venda de jogadores, bem como em relação a empréstimos de jogadores entre clubes.

As transferências de jogadores são hoje responsáveis por uma movimentação de cerca de 25 bilhões de euros na temporada 2016/2017[Deloitte 2016]. Entretanto, o valor de um jogador está associado não apenas as suas habilidades em seus clubes, mas também está associado ao seu desempenho na sua seleção nacional. Desta forma, eventos como a Copa do Mundo e torneios continentais tem suma importância na definição do valor de um atleta. A Copa do Mundo de Futebol se destaca, por ser o segundo maior evento esportivo em escala global [Baade and Matheson 2004], sendo superado apenas pelas Olimpíadas. Dado as grandes proporções do evento, ela tem grande influência no mercado de transações de jogadores [Felix et al. 2018], o que gera uma grande quantidade de notícias na mídia nacional e internacional (e.g., [Iandoli 2018, Martin 2018]).

Em virtude destes fatos, este trabalho tem como objetivo estudar as propriedades da rede de transferências de jogadores de futebol entre os países presentes na Copa do Mundo de Futebol utilizando dados do mercado de transferências de jogadores entre 1990 e 2018. Por meio deste estudo, foi realizada uma caracterização do futebol mundial, mostrando os países mais importantes e diferentes tipos de mercados gerados pelo dinamismo econômico das transferências de atletas.Para realização do mesmo, foram utilizadas técnicas de redes complexas, avaliando os principais países e mercados de transferências de jogadores, foram feitas ainda algumas análises do pós copa do mundo, avaliando os países que ficaram melhores colocados na Copa do Mundo 2018, sendo estes França, Croácia, Bélgica e Inglaterra.

O restante do artigo está organizado da seguinte forma. A seção 2 apresenta uma visão dos trabalhos correlatos, enquanto a Seção 3 apresenta brevemente os conceitos utilizados e descreve a metodologia de coleta, tratamento e análise de dados. A Seção 4

\footnotetext{
${ }^{1}$ Www.transfermarkt.com

iSys: Revista Brasileira de Sistemas de Informação (iSys: Brazilian Journal of Information Systems) http://seer.unirio.br/index.php/isys/
} 
apresenta e discute os resultados obtidos. Finalmente, a Seção 5 apresenta as conclusões obtidas por este trabalho e sugestões de trabalhos futuros.

\section{Trabalhos Relacionados}

O futebol tem sido alvo de estudos científicos há várias décadas. A maioria dos estudos sobre o tema surge na área da Educação Física, estes estudos analisam a biomecânica do esporte [Lees et al. 2010], métodos de treinamento e rendimento esportivo [González-Badillo et al. 2015], além da medicina e da nutrição esportiva [Osgnach et al. 2010]. Um segundo ramo de pesquisas bem difundido analisa o futebol a partir de uma visão sociológica e antropológica, utilizando-o para estudar temas correlatos, como a migração internacional de trabalhadores [Magee and Sugden 2002], a transformação cultural imposta pelo futebol [Redhead 2002] ou questões sociais, como o racismo [Jarvie 2003] e a violência [Taylor 2014].

Poucos trabalhos na literatura buscaram entender, analisar e avaliar o mercado de transferências de jogadores de futebol. Dentre eles, pode-se destacar o trabalho de [Palacios-Huerta 2004], que avaliou as transações de jogadores por meio de análises estatísticas comportamentais temporais na liga de futebol inglesa. Além disto [Frick 2007], analisou o mercado de transferências europeu, de maneira empírica, avaliando diversos atributos que compõe um atleta do futebol como o salário e tempo de carreira.

Os trabalhos de [Liu et al. 2016, Félix et al. 2018, Felix et al. 2018] avaliaram a rede de transferências de jogadores utilizando redes complexas. O primeiro destes trabalhos foi o de [Liu et al. 2016], que construiu e realizou a análise da rede de transferências entre jogadores das 24 maiores ligas do mundo, durante o período de 2011 a 2015, objetivando avaliar o sucesso dos times de acordo com suas transações passadas.

O trabalho de [Felix et al. 2018] propôs uma métrica de junção de rankings de centralidade e os utilizou para avaliar os principais mercados de compra e venda de jogadores de futebol. Além disto, este trabalho também apresentou uma visão sociológica do futebol, realizando uma análise quantitativa de teorias sociológicas desenvolvidas por outros autores.

Em [Félix et al. 2018], assim como neste trabalho, é realizada uma caracterização e uma análise da rede de transferência de jogadores de futebol, avaliando mercados e tendências do mercado de transações de jogadores utilizando técnicas de redes complexas. Este trabalho se destaca dos anteriores por apresentar uma proposta de avaliação mais aprofundada dos países melhores colocados na Copa do Mundo 2018.

\section{Metodologia}

Este trabalho possui como objetivo uma avaliação do mercado de transferências de jogadores de futebol. Para isto, foi desenvolvida uma metodologia que combina coleta de dados, organização de dados e técnicas de redes complexas, como ilustra a Figura 1. De maneira geral, é possível dividir a proposta em três etapas distintas: $(i)$ coleta de dados, que consiste no desenvolvimento de um método automático para captura e armazenamento de dados de transferências de jogadores a partir da web; (ii) modelagem da rede, etapa onde são construídos os grafos que representam as redes de transações entre países; e (iii) análise das redes, que compreende a utilização de algoritmos de redes complexas para análise e verificação dos dados. 


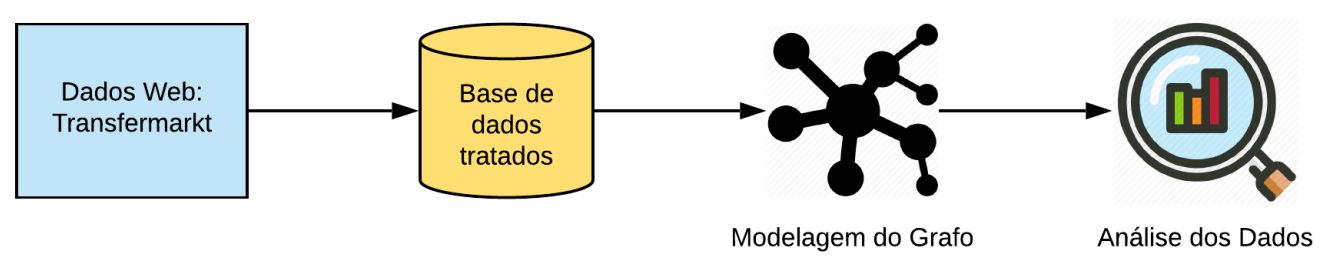

Figura 1. Etapas da abordagem proposta

A seguir são apresentadas de maneira detalhada as etapas da metodologia proposta.

\subsection{Coleta de dados}

Para realização da coleta de dados foi utilizado o website Transfermarkt. O Transfermarkt possui um banco de dados atualizado com diversas informações relacionadas ao futebol, como tabelas de campeonatos, desempenho de jogadores, estatísticas sobre os mais diversos temas, transferências de jogadores, dentre outros dados futebolísticos.

Para coletar os dados relativos a transferências de jogadores, foi desenvolvido um crawler web. O crawler desenvolvido navega pelas páginas do Transfermarket e realiza o download de todo o código html contendo os dados relevantes para os estudos deste trabalho.

Após a coleta de dados, foi preciso desenvolver um parser de forma a tratar os dados coletados. Este parser foi responsável por identificar entre os dados as informações úteis e armazená-las em um formato estruturado, de forma a facilitar a posterior modelagem da rede.

Foram coletados dados referentes a transferências de jogadores entre os anos de 1962 e 2017. Para cada ano, foi realizada a coleta de um máximo de 250 transações de compra e venda para jogadores de cada posição (goleiro, zagueiro, lateral-esquerdo, lateral-direito, meio de campo, atacante), ordenadas de forma decrescente pelo valor da transação. A Tabela 1 mostra o número de transações coletadas, por período, para cada posição.

Pode-se observar que foram coletadas cerca de 28 mil transferências de jogadores, sendo grande maioria de atacantes e meio campistas. Percebe-se também que o número de transferências tem aumentado cada vez mais por ano, sendo este um indicador da expansão do mercado de transações como mostrado em [Felix et al. 2018] .

\subsection{Modelagem da Rede}

Seja $S=\left\{s_{1}, \cdots, s_{n}\right\}$ a lista de seleções participantes da Copa do Mundo de Futebol 2018. A rede de transferências de jogadores foi modelada como um grafo $G=(V, A)$, onde cada vértice $v_{i} \in V$ representa um país $s_{i} \in S$ e cada arco $a_{i j} \in A$ representa a relação de venda de um jogador do país $s_{i}$ para o país $s_{j}$. Além disto, uma função $f: a_{i j} \mapsto p_{i j}$ associa cada arco $a_{i j} \in A$ com um peso $p_{i j} \geq 0$ que representa a quantidade de vendas de jogadores realizadas do país $s_{i}$ para o país $s_{j}$, caso exista transações naquela 


\begin{tabular}{|c|c|c|c|c|c|c|}
\hline Período & \multicolumn{6}{|c|}{ Posição } \\
\hline & Goleiro & Zagueiro & LateralEsquerdo & LateralDireito & МeioCampo & Atacante \\
\hline $1962-1965$ & 0 & 2 & 2 & 0 & 6 & 22 \\
\hline 1966-1969 & 3 & 9 & 2 & 0 & 21 & 26 \\
\hline $1970-1973$ & 6 & 11 & 5 & 2 & 34 & 50 \\
\hline 1974-1977 & 9 & 20 & 3 & 5 & 51 & 79 \\
\hline $1978-1981$ & 15 & 43 & 17 & 12 & 93 & 122 \\
\hline $1982-1985$ & 15 & 41 & 12 & 8 & 85 & 125 \\
\hline 1986-1989 & 32 & 132 & 23 & 23 & 177 & 213 \\
\hline 1990-1993 & 104 & 131 & 56 & 78 & 294 & 318 \\
\hline 1994-1997 & 183 & 254 & 74 & 111 & 475 & 489 \\
\hline 1998-2001 & 240 & 450 & 156 & 163 & 805 & 920 \\
\hline $2002-2005$ & 233 & 584 & 189 & 207 & 1037 & 1111 \\
\hline 2006-2009 & 462 & 1000 & 432 & 425 & 2192 & 1716 \\
\hline 2010-2013 & 390 & 973 & 364 & 367 & 1966 & 1997 \\
\hline 2014-2017 & 395 & 903 & 382 & 352 & 1923 & 2084 \\
\hline
\end{tabular}

Tabela 1. Propriedades das comunidades geradas por cada algoritmo em cada rede

direção. Foi gerada uma única rede que compreende as transferências realizadas entre os anos de 1990 à 2018. A escolha do período que foi utilizado para modelagem da rede deu-se pela maior quantidade de transferências realizadas durante este período, sendo os valores anteriores ao ano de 1990 muito pequenos para análises mais profundas.

\subsection{Análise da rede}

De forma a analisar as redes geradas, este trabalho realizou a divisão dos países em comunidades. Cada comunidade compreende um grupo de países que possuem um número de transferências alto entre si quando comparado com os países das demais comunidades da rede [Félix et al. 2018]. Para realizar a detecção de comunidades, este trabalho utilizou três diferentes algoritmos: (i) Multilevel [Blondel et al. 2008]; (ii) um algoritmo baseado em autovetores (Eigenvector [Newman 2006]); e (iii) Fastgreedy [Clauset et al. 2004]. Todos os três algoritmos tem como princípio básico a maximização da modularidade [Newman and Girvan 2004], que é uma métrica bem estabelecida na literatura para avaliar da qualidade de divisão da rede. Desta forma, quanto maior a medida de modularidade da rede, mais consistente é a estrutura de comunidade da rede. A motivação para utilização destas técnicas se dá por estas serem abordagens difundidas na literatura, as quais possuem fácil acesso para replicação por estarem disponíveis em diversas bibliotecas. Abaixo é apresentado o funcionamento destes métodos de forma sintetizada.

- Multilevel: Este algoritmo funciona de maneira aglomerativa e opera em duas etapas para a partição de um grafo. A primeira etapa considera que cada vértice é uma comunidade e, iterativamente, são adiciona arestas entre vértices onde há 
maiores ganhos de modularidade. Já a segunda etapa constrói uma nova rede considerando as comunidades geradas na etapa anterior como vértices e as ligações entre os vértices de diferentes comunidades como arestas dessa nova rede. Este processo se repete até que não haja mais ganho de modularidade global.

- Eigenvector: Este algoritmo funciona de maneira divisiva e utiliza uma técnica de partição de grafos a partir de uma matriz laplaciana. Desta forma, ele manipula uma matriz espectral, que representa uma matriz de modularidades, e de forma iterativa calcula o autovetor associado ao maior autovalor em módulo desta matriz. Logo após é feita uma bipartição, onde cada uma das partições são novamente bipartidas até que não haja mais ganho de modularidade com a nova divisão.

- Fastgreedy: Este algoritmo trabalha por meio de uma estrutura hierárquica para a detecção de comunidades, sendo a estrutura o dendrograma. Inicialmente cada vértice é considerado uma comunidade, a cada passo, através de uma estratégia heurística gulosa, realiza-se a combinação de duas comunidades cuja união resulte em um maior ganho de modularidade. Ao final da execução, haverá apenas uma grande comunidade com todos os vértices, então escolhe-se o corte no dendrograma que resulta na maior modularidade.

Além das análises para detecção de comunidades, foram utilizadas neste trabalho métricas de centralidade de vértices, que avaliam a relevância de um vértice para o grafo gerado. Neste contexto, avaliou-se a importância de um país para o mercado de transferências de jogadores. Para realização de tal análise foram utilizadas três técnicas principais de centralidade, sendo elas as técnicas de Closeness, Betwenness e Pagerank, entretanto, ressalta-se que existem diversas outras métricas que indicam a centralidade de um vértice em uma rede.

Os algoritmos de centralidade de rede utilizados na abordagem proposta, empregam diferentes abordagens para análise do quão central é um vértice, sendo estes definidos abaixo:

- Closeness: avalia a distância geodésica média entre um vértice e outros por ele alcançáveis [Freeman 1978];

- Betweenness: analisa a fração de caminhos mínimos, considerando a distância geodésica entre todos pares de vértices da rede passa por cada vértice, o vértice mais central será o que possui a maior fração de caminhos passando por ele [Freeman 1977];

- Pagerank: considera que a centralidade propagada aos vizinhos é proporcional ao número de arestas de saída [Page et al. 1999];

Vale destacar que devido a natureza dos algoritmos, para aplicação das técnicas de Betweenness e Closeness, foi preciso inverter os valores dos pesos das arestas. A inversão foi feita pois essas medidas possuem como base os caminhos mínimos e utilizando uma abordagem tradicional de ponderamento de arestas a precisão sobre os principais países da rede seria alterada não representando a realidade sobre a relevância de um vértice no grafo.

O restante das análises foram realizadas avaliando as propriedades da rede gerada, sendo estas a densidade, diâmetro, coeficiente de clusterização, reciprocidade, assortatividade de grau, entre outras, as quais serão apresentadas à medida que seus resultados forem apresentados na seção 4. 


\section{Resultados}

\subsection{Propriedades da Rede de Transferências}

Nesta seção é apresentado como as técnicas de redes complexas podem auxiliar na compreensão dos dados e em avaliações importantes sobre o mercado de transferências de jogadores de futebol.

\begin{tabular}{|r|r|}
\hline Propriedade & Valor \\
\hline Densidade & 0,40 \\
\hline Diâmetro & 4 \\
\hline Reciprocidade & 0,71 \\
\hline Assortatividade grau & $-0,22$ \\
\hline Grau máximo & 46 \\
\hline Força máxima de saída & 521 \\
\hline Força máxima de entrada & 1034 \\
\hline
\end{tabular}

Tabela 2. Propriedades da rede de países da Copa

Na Tabela 2, é possível ver as propriedades da rede gerada. A densidade da rede é a razão entre a quantidade de arestas do grafo e a quantidade de arestas do grafo completo com o mesmo número de vértices, desta forma quanto mais perto de um, mais ligado são os nós. Na rede gerada, essa medida ficou próxima a 0,4 , o que nos mostra que a maioria dos países não fazem transações entre si.

Por meio do diâmetro, que representa a maior distância entre qualquer par de vértice, evidencia-se também a separação entre os países da rede, já que o mesmo possui um valor igual a 4, o que mostra que seriam necessários este valor em saltos para que um jogador chegasse em um país $X$ saindo de um país $Y$. Isso nos mostra que no pior caso, um jogador precisaria passar em 4 países além de seu país de origem para depois conseguir jogador em um país $Y$.

Esta propriedade, juntamente com a reciprocidade, que é a métrica da possibilidade de que dos vértices de um grafo direcionado serem mutuamente ligados, nos informa que a rede é mútua, já que seu valor é de 0,71 , o que mostra que países que compram $X$ vendem para este país $Y$ e vice-versa. Entretanto, destaca-se que a intensidade dessas transações, representadas pelo peso da arestas, são em grande maioria divergentes, sendo que poucos países conseguem comprar na mesma intensidade com que vendem para o mesmo país.

Evidencia-se que a rede por ser modelada como a junção de transações ocorridas entre 1990 e 2017, possui transferências que ocorreram em diferentes anos entre dois países, sendo estas associadas como uma transação geral. Isso corrobora para o fato da rede gerada ter um valor reciprocidade alto. Além disso, o estudo visa a avaliação de países presentes na Copa do Mundo 2018, sendo os times presentes nesta, considerados os melhores do mundo. Além disto, grande parte destes países possuem uma tradição no futebol, o que faz com que consequentemente partes dos países tenham uma grande movimentação de jogadores, sendo assim um mercado movimentado.

Entretanto, ao analisar a rede temporalmente, como feito em [Felix et al. 2018], percebe-se que as ligações dos grafos são pouco recíprocas, mostra-se assim que países 


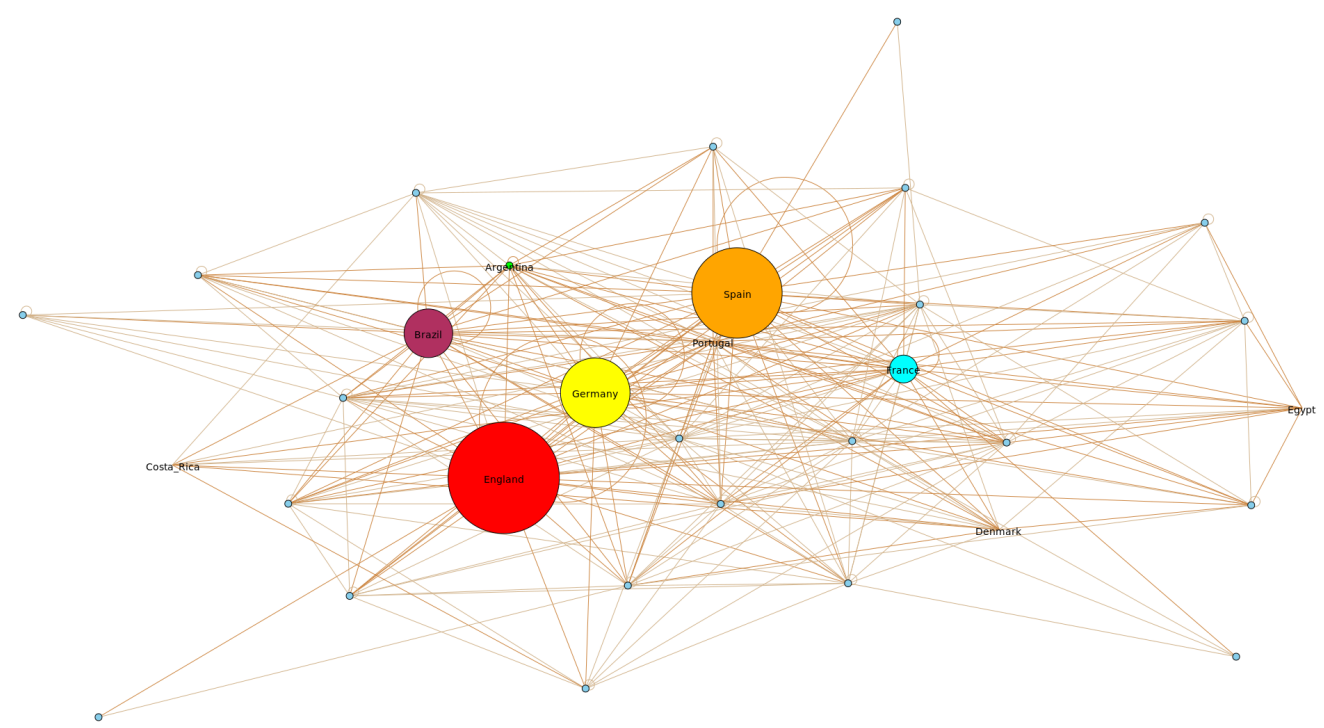

Figura 2. Plot da rede com foco nos principais vértices identificados pelo algoritmo de Betweenness

que são mercados fazenda não possuem valores que lhe permitam a compra de jogadores de países consumidores, participantes de ligas ricas.

A assortatividade de grau se dá pela tendência de um um nó ter uma ligação com outros nós parecidos com ele. Neste estudo este valor é muito baixo, sendo esta uma rede não assortativa, transparecendo assim que países com muitas ligações tendem a realizar transações com países de poucas transferências, corroborando com os fatos mostrados anteriormente [Félix et al. 2018, Liu et al. 2016].

O grau máximo da rede nos revela alguns dos países de grande relevância no futebol mundial: França e Alemanha. Por meio dessa métrica é possível observar os países que possuem o maior número de parceiros para compra e venda de jogadores. A força máxima de saída é 521, referindo-se ao total de vendas internacionais na rede de um país, o Brasil. Ou seja, o Brasil é o país que mais forneceu jogadores para os clubes dos países que estão na Copa. Por outro lado, o país que mais comprou jogadores de outros países foi a Inglaterra, que possui a força máxima de entrada da rede, 1034. Mostra-se assim que o Brasil é um país tipicamente produtor de talentos, e a Inglaterra um país especializado em compra de jogadores de diferentes origens.

\subsection{Análise de centralidade}

Algoritmos de centralidade de rede calculam a importância de um vértice na rede, sendo esta uma técnica importante para a identificação de quais são os principais países nos mercados de transferências de jogadores. Neste trabalho, utilizou-se de três algoritmos conhecidos para identificação de vértices centrais, sendo estes: Closeness [Freeman 1978], Betweenness [Newman and Girvan 2004] e PageRank [Page et al. 1999].

Após o cálculo das medidas de centralidade para a rede, foram obtidos três listas ordenadas distintas, das quais a Tabela 3 apresenta as 10 primeiras posições. Pode-se ver também em 4.2 uma figura da rede gerada considerando os principais vértices identificados pelo algoritmo Betweenness. 


\begin{tabular}{|r|r|r|r|}
\hline Posição & Closeness & Betweenness & PageRank \\
\hline 1 & Inglaterra & Inglaterra & Inglaterra \\
\hline 2 & Alemanha & Espanha & Alemanha \\
\hline 3 & Espanha & Alemanha & Espanha \\
\hline 4 & França & Brasil & Rússia \\
\hline 5 & Suíça & França & França \\
\hline 6 & Rússia & Argentina & Brasil \\
\hline 7 & Bélgica & Portugal & Bélgica \\
\hline 8 & Argentina & Costa Rica & Portugal \\
\hline 9 & Brasil & Dinamarca & Polônia \\
\hline 10 & Dinamarca & Egito & México \\
\hline
\end{tabular}

Tabela 3. Top-10 países ordenados por cada uma das medidas de centralidade.

Como é possível observar a partir da Tabela 3, há uma grande consistência entre as medidas de centralidade consideradas e os rankings obtidos apresentam poucas variações. Cinco países aparecem entre as 10 primeiras posições nas três listas, e estão em negrito na Tabela 3, assim como na Tabela 4. As maiores surpresas ocorreram na lista ordenada pela medida Betweenness, mostrando Egito e Costa Rica, que são grandes parceiros da Inglaterra.

A Tabela 4 mostra a quantidade de transações realizadas pelos 10 países que mais realizaram transações internacionais dentro da rede. Percebe-se que todos países presentes nesta Tabela também estão presentes em pelo menos um dos rankings apresentados pela Tabela 3, desta forma pode-se considerar que a importância dos países na rede está diretamente ligada ao número de transações internacionais realizadas.

\begin{tabular}{|r|r|r|}
\hline Posição & País & \# de transações \\
\hline 1 & Inglaterra & 1384 \\
\hline 2 & Alemanha & 1230 \\
\hline 3 & Espanha & 1096 \\
\hline 4 & França & 925 \\
\hline 5 & Brasil & 719 \\
\hline 6 & Portugal & 691 \\
\hline 7 & Argentina & 513 \\
\hline 8 & Rússia & 453 \\
\hline 9 & Bélgica & 416 \\
\hline 10 & Suíça & 337 \\
\hline
\end{tabular}

Tabela 4. Quantidade de transações por país

\subsection{Análise de comunidades}

Para a identificação de "submercados"que realizam grandes quantidades de transferências, foi utilizado neste trabalho algoritmos de detecção de comunidades, este conseguem identificar grupos coesos de vértices dentro de uma rede. Os vértices desses subgrupos possuem como característica principal o fato de seus vértices possuírem um número de ligações maior entre si do que com vértices fora deste subgrupo, formando assim as chamadas comunidades. 
Apesar do mercado de transferências de jogadores ser um mercado abrangente, onde há o intercâmbio livre entre jogadores, existem alguns "padrões de consumo"que podem ser observados, dado que países ricos procuram talentos estrangeiros para seus times locais em um grupos semelhantes de países. A motivação para a detecção de comunidades é tentar identificar esses padrões.

A Tabela 5 mostra os resultados encontrados por cada um dos métodos, em termos do valor de modularidade e do número de comunidades.

\begin{tabular}{|r|r|r|}
\hline Algoritmo & Modularidade & \# de comunidades \\
\hline Eigenvector & 0.53 & 8 \\
\hline Fastgreedy & 0.14 & 6 \\
\hline Multilevel & 0.54 & 7 \\
\hline
\end{tabular}

Tabela 5. Comparação entre algoritmos de comunidade

Considerando que os métodos para identificação de comunidades visam maximizar a modularidade, a análise da Tabela 5 permite identificar que o método Multilevel oferece uma partição de melhor modularidade entre os métodos analisados e, por isso, essa partição foi escolhida para as análises seguintes.

\begin{tabular}{|r|r|}
\hline Comunidade & Países \\
\hline 1 & Rússia, Polônia, Sérvia e Panamá \\
\hline 2 & Egito, Tunísia, Arábia Saudita, Nigéria e Marrocos \\
\hline 3 & Irã, Bélgica, Croácia, Dinamarca, Costa Rica, Suécia e Austrália \\
\hline 4 & Brasil, México, Espanha, Portugal, Argentina, Japão \\
Coreia do Sul, Uruguai,Colômbia e Peru
\end{tabular}

Tabela 6. Comunidades formadas

A Figura3 apresenta uma representação gráfica da rede de transferências com as comunidades identificadas através de cores.

A comunidade 1, formada por Rússia (país anfitrião dessa copa do mundo), Polônia, Sérvia e Panamá, possui apenas um entre os países com maior número de transferências registradas na base (Tabela 4), sendo este a Rússia, com 882 transações. Polônia e Sérvia possuem 428 e 308 transferências respectivamente. Já o Panamá, possui apenas duas transações registradas com outros países participantes da copa, sendo uma com a Polônia, o que ajuda a explicar o porquê da presença do Panamá neste grupo.

Para auxiliar na análise dos dados e ilustrar o montante movimentado por um país, foi considerada a balança comercial do mesmo. Entende-se como balança comercial de um país a diferença entre o somatório dos valores das compras e vendas de jogadores no período estudado. Uma balança comercial negativa indica que o país tem uma liga de futebol forte economicamente, podendo ser considerado como mercado consumidor de atletas. Se encaixam nesta categoria países como a Inglaterra e a Espanha. Já uma balança comercial positiva indica que o país vende uma grande quantidade de jogadores, 


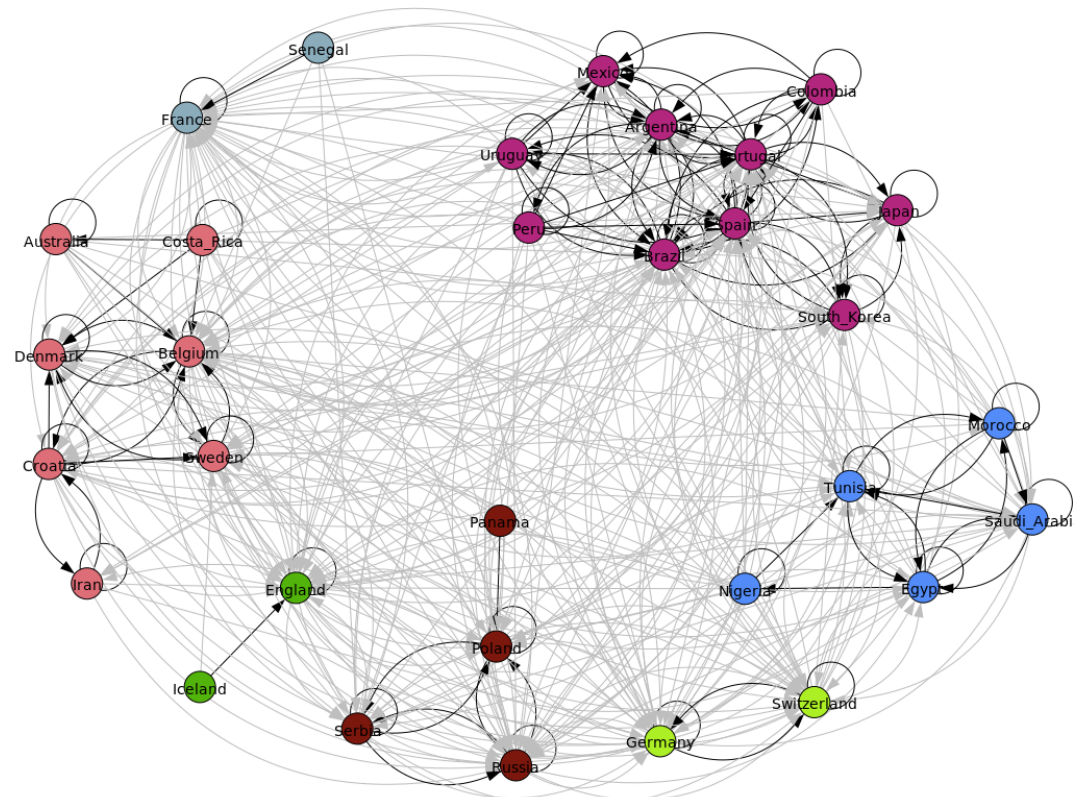

Figura 3. Rede de transferências de jogadores de futebol entre países da copa do mundo dividida em comunidades

\begin{tabular}{|r|r|r|r|r|}
\hline País & Vendas & Compras & Balança & \# de transferências \\
\hline Rússia & Inglaterra,Alemanha,Espanha & Brasil,Portugal,Sérvia & $-757416000 €$ & 882 \\
\hline Polônia & Alemanha,Rússia,Inglaterra & Sérvia,Alemanha,Croácia & $163645000 €$ & 428 \\
\hline Sérvia & Rússia,Alemanha,Espanha & Brasil,Rússia,Portugal & $466825000 €$ & 308 \\
\hline Panamá & Espanha,Polônia & - & $790000 €$ & 2 \\
\hline
\end{tabular}

Tabela 7. Dados sobre os países presentes na comunidade 1

e são comumente descritos como "mercados fazenda". Estes mercados fazenda são caracterizados pela formação e exportação de jovens e talentosos jogadores. Se encaixam nesta categoria países como o Brasil, a Argentina e o México.

A Tabela 7 analisa os países presentes na comunidade 1, apresentando os países que mais compram de cada país de referência, os países que mais vendem para aquele país, a balança comercial e a quantidade de transferências realizadas por aquele país.

A análise dos países com os quais os integrantes da comunidade 1 realizam transferências com maior frequência, permite observar o motivo da ligação entre os mesmos. De acordo com a balança comercial do país, é possível ver qual sua posição com relação aos outros países, se é um país consumidor ou um país fornecedor de atletas.

É possível perceber que, nessa comunidade, todos os países estão conectados pelos seus compradores e fornecedores, sendo a Rússia o principal país da comunidade, por possuir a maior quantidade de transações e estar entre os principais parceiros comerciais de cada um dos países, com exceção do Panamá. Desta forma observa-se que a movimentação financeira dos três primeiros países é consideravelmente grande, sendo a Rússia, o único país presente na comunidade com a balança comercial negativa, um país consumidor, que possui clubes ricos que buscam atletas em outros países, enquanto os outros países Polônia e Sérvia são países produtores de talentos por possuírem uma balança comercial positiva. 
A comunidade 2 é formada por Egito, Tunísia, Arábia Saudita, Nigéria e Marrocos, sendo que apenas a Arábia Saudita não pertence ao continente africano. Nesta comunidade, como pode-se observar na Tabela 8 , os países não possuem uma grande quantidade de transferências e nenhum dos países presentes nessa comunidade se equipara, em número de transações realizadas, com grandes países da Europa e América. Além disso, assim como na comunidade 1 , a maioria dos países possui a balança comercial positiva. Provavelmente esses países trocam frequentemente de jogadores entre si devido a proximidade geográfica deles, e essas transações foram suficientes para considerá-los como integrantes de uma comunidade.

\begin{tabular}{|r|r|r|r|r|}
\hline País & Vendas & Compras & Balança & \# de transf. \\
\hline Tunísia & França,Arábia Saudita,Suíça & Nigéria,França,Marrocos & $39491000 €$ & 190 \\
\hline Egito & Arábia Saudita,Inglaterra,Suíça & Tunísia,Portugal,Inglaterra & $48775000 €$ & 164 \\
\hline Arábia Saudita & Brasil,Suíça,Rússia & Brasil,Egito,Tunísia & $-166437000 €$ & 123 \\
\hline Nigéria & Tunísia,França,Alemanha & Egito & $22035000 €$ & 35 \\
\hline Marrocos & França,Tunísia,Arábia Saudita & Egito,França,Tunísia & $27789000 €$ & 68 \\
\hline
\end{tabular}

Tabela 8. Dados sobre os países presentes na comunidade 2

A comunidade 3, formada por Irã, Bélgica, Croácia, Dinamarca, Costa Rica, Suécia e Austrália é a comunidade com maior diversidade de continentes, tendo países pertencentes a Europa, América, Ásia e Oceania. Essa comunidade é caracterizada por possuir somente países com uma balança comercial totalmente positiva, como pode ser observado de maneira detalhada pela Tabela 9.

\begin{tabular}{|r|r|r|r|r|}
\hline País & Vendas & Compras & Balança & \# de transf. \\
\hline Irã & Alemanha,Rússia,Inglaterra & Brasil,Rússia,Espanha & $7607000 €$ & 41 \\
\hline Bélgica & Inglaterra,Alemanha,França & França,Alemanha,Croácia & $500960000 €$ & 627 \\
\hline Croácia & Alemanha,Bélgica,Rússia & Alemanha,Bélgica,Brasil & $406378000 €$ & 286 \\
\hline Dinamarca & Alemanha,Inglaterra,Suécia & Alemanha,Suécia,Inglaterra & $247644000 €$ & 354 \\
\hline Costa Rica & México,Bélgica,Inglaterra & Brasil & $13645000 €$ & 13 \\
\hline Suécia & Inglaterra,Alemanha,Dinamarca & Dinamarca,Inglaterra,Alemanha & $260493000 €$ & 188 \\
\hline Austrália & Inglaterra,Alemanha,Japão & Costa Rica & $23305000 €$ & 37 \\
\hline
\end{tabular}

Tabela 9. Dados sobre os países presentes na comunidade 3

A Tabela 9 mostra que os países europeus possuem uma quantidade maior de transações e, consequentemente, um maior valor na balança comercial. Estes países funcionam como um trampolim para futura venda de jogadores para outros países europeus, envolvendo times de maior prestígio.

Das poucas transações presentes na Oceania a maioria são transações de venda. $\mathrm{O}$ continente possui 62 transações de venda e 7 transações de compra registradas, fazendo desse continente o que possui menor quantidade de transações nesta comunidade.

Na Tabela 10, a distribuição de transações por continente é apresentada.

A comunidade 4 é a maior comunidade presente na rede, com um total de 10 países. Essa comunidade é caracterizada pela presença de países de diversos continentes como Brasil, México, Argentina, Uruguai, Colômbia e Peru, representando a América, 


\begin{tabular}{|l|r|r|r|}
\hline Continente & \# compras & \# vendas & \# internas \\
\hline Asia & 834 & 281 & 539 \\
\hline América & 435 & 1853 & 1296 \\
\hline Africa & 60 & 388 & 384 \\
\hline Europa & 2222 & 966 & 21057 \\
\hline Oceania & 7 & 62 & 4 \\
\hline
\end{tabular}

Tabela 10. Quantidade de transações de cada continente

Japão e Coreia do Sul representando Ásia e, ainda, Espanha e Portugal representando a Europa.

A Tabela 11 apresenta os dados dos países presentes na comunidade 4 . Nesta comunidade, está presente uma maior quantidade de países vencedores de copas do mundo, sendo eles Brasil, Argentina, Espanha e Uruguai.

\begin{tabular}{|r|r|r|r|r|}
\hline País & Vendas & Compras & Balança comercial & \# de transf. \\
\hline Espanha & Inglaterra,Alemanha,Portugal & Argentina,Inglaterra,Portugal & $-906437000 €$ & 1704 \\
\hline Portugal & Espanha,Inglaterra,França & Brasil,Espanha,Argentina & $1468658000 €$ & 871 \\
\hline Brasil & Alemanha,Portugal,Espanha & Argentina,Portugal,Espanha & $2257058000 €$ & 1133 \\
\hline Argentina & Espanha,México,Brasil & Espanha,Uruguai,México & $1491868000 €$ & 794 \\
\hline México & Argentina,Brasil,Espanha & Argentina,Brasil,Colômbia & $-72455000 €$ & 298 \\
\hline Japão & Alemanha,Brasil,Inglaterra & Brasil,Alemanha,Coreia do Sul & $42627000 €$ & 144 \\
\hline Uruguai & Espanha,Argentina,Portugal & Brasil,Argentina,Espanha & $328424000 €$ & 122 \\
\hline Colômbia & Argentina,Brasil,México & México,Argentina,Brasil & $188658000 €$ & 89 \\
\hline Peru & Alemanha,México,Portugal & Argentina & $22703000 €$ & 27 \\
\hline Coreia do Sul & Alemanha,Japão,Inglaterra & Brasil,Sérvia,Croácia & $58499000 €$ & 73 \\
\hline
\end{tabular}

Tabela 11. Dados sobre os países presentes na comunidade 4

Assim como na comunidade 1, apenas uma pequena parte da comunidade possui uma balança comercial negativa, sendo estes Espanha e México.

Como esta comunidade possui um número bem grande países, optou-se por analisar a mesma por continente. Primeiramente, analisando os países da América, que são maioria nessa comunidade, observa-se que o Brasil possui o maior número de transações e o Peru o menor número de transações. Através dessa comunidade é possível visualizar um padrão que é compartilhado pela maioria dos países da América do Sul e América Central que é a balança comercial positiva, demonstrando a falta de poder de compra dos clubes pertencentes a esses países para trazer atletas de outros continentes ou mesmo manter atletas de origem nacional de qualidade dentro do próprio país.

A América hoje possui a maior média de venda de jogadores entre todos os continentes, como pode-se ver na Tabela 12, sendo que considerando apenas transações externas de compra e venda, cerca de $81 \%$ das transações deste continente são transações de venda. Desta forma a Tabela 12 corrobora que este é um mercado produtor de talentos para clubes de outros países com poder aquisitivo maior.

Analisando os países asiáticos presentes na comunidade, tendo Japão e Coreia do Sul como representantes nesta comunidade, observa-se que ambos possuem uma balança comercial positiva, o que não representa o padrão de consumo asiático como um todo, 


\begin{tabular}{|r|r|}
\hline Continente & Valor médio vendas \\
\hline Asia & $1.535 .288 €$ \\
\hline América & $2.894 .209 €$ \\
\hline Africa & $604.533 €$ \\
\hline Europa & $2.202 .635 €$ \\
\hline Oceania & $415.322 €$ \\
\hline
\end{tabular}

Tabela 12. Valor médio pago em transações por continente

pois a maioria das movimentações de compra superam as de venda. Esse padrão é alavancado pela China, que lidera como país com maior transações gerais dentro da Ásia movimentando grandes quantidade financeiras com grandes contratações de jogadores estrangeiros ${ }^{2}$. A China, entretanto, mesmo sendo um país com fluxo considerável no mercado de transação de atletas não está presente entre os países classificados para copa de 2018, o que aponta que não são apenas investimentos em jogadores estrangeiros para fortalecimento das competições nacionais que influenciam no desempenho da seleção para classificação e participação em uma copa do mundo.

Os países do continente europeu nesta comunidade são Espanha e Portugal. Neste grupo fica claro o domínio de alguns países pertencentes a esse continente no mercado de transações. Cada um dos países presentes nesta comunidade funciona como um agente diferente na rede estudada e no mercado como um todo. A Espanha é um país comprador de talentos para fortalecimento do campeonato nacional, de forma que os clubes pertencentes a esses países adquirem tais atletas sem pensar em uma eventual venda do jogador. Portanto, a Espanha possui uma balança negativa, abrigando alguns dos clubes mais ricos do mundo ${ }^{3}$, que dispõem de montantes significativos para manter os atletas dentro de seu domínio e sempre comprar novos reforços para manutenção dos clubes.

Já Portugal tem servido como vitrine para os atletas, que passam pelos clubes portugueses para ter maior visibilidade no mercado europeu ao atuar neste país, servindo como um mercado impulsionador de atleta, aumentando atributos e o valores dos jogadores. Geralmente, times portugueses compram jogadores com o objetivo da venda por um preço maior que o comprado, obtendo assim um lucro na venda do jogador fazendo, assim, que Portugal possua uma balança comercial positiva.

Hoje a Europa é o centro do futebol mundial, onde há as principais ligas, com os melhores jogadores do mundo ${ }^{4}$. Grande parte dos países europeus com balança comercial positiva funcionam como país trampolim para uma posterior venda desses jogadores. Entretanto, isso não ocorre com todos os países, já que com a consolidação de campeonatos mais fortes devido a compra de jogadores de maior habilidade faz com que o nível dessas competições aumente, fazendo com que haja uma evolução dos jogadores e dos preços de venda do atleta. Para uma melhor visualização disso, foi analisada a média de compra e venda nesses países.

Pode-se ver na Tabela 13 a média de compra e vendas dos países pertencentes a

\footnotetext{
${ }^{2}$ www.theguardian.com/football/these-football-times/2017/jan/05/china-chinese-super-league-oscarcarlos-tevez

${ }^{3}$ http://uk.businessinsider.com/the-20-richest-football-clubs-in-the-world-2017-1

${ }^{4}$ http://www.fifa.com/the-best-fifa-football-awards/fifa-fifpro-world11/index.html
} 


\begin{tabular}{|r|r|r|}
\hline País & Vendas & Compras \\
\hline Rússia & $1.681 .381 €$ & $1.830 .670 €$ \\
\hline Polônia & $693.962 €$ & $268.694 €$ \\
\hline Sérvia & $972.090 €$ & $408.254 €$ \\
\hline Espanha & $3.128 .515 €$ & $2.907 .998 €$ \\
\hline Portugal & $2.089 .052 €$ & $1.975 .059 €$ \\
\hline Bélgica & $1.738 .789 €$ & $1.022 .196 €$ \\
\hline Croácia & $1.090 .413 €$ & $646.089 €$ \\
\hline Dinamarca & $1.503 .512 €$ & $943.660 €$ \\
\hline Suécia & $1.124 .419 €$ & $418.479 €$ \\
\hline Alemanha & $1.529 .849 €$ & $1407114 €$ \\
\hline Suíça & $1.337 .964 €$ & $908.760 €$ \\
\hline Inglaterra & $2.886 .619 €$ & $3.013 .590 €$ \\
\hline França & $2.098 .838 €$ & $2.145 .160 €$ \\
\hline Islândia & $278.750 €$ & $0 €$ \\
\hline
\end{tabular}

Tabela 13. Tabela mostra o valor médio pago em transações por continente

Europa que estão presentes na copa do mundo 2018. De forma parcial pode-se ver países que compram jogadores por uma média mais baixa e vende a um preço mais alto. Ao associar essa informação a dados de balança comercial e aos países ao qual esse país se associa para fazer compras, pode-se definir se esse é um país consumidor ou fornecedor.

\subsection{Análise Pós-Copa: Avaliação dos melhores colocados na Copa}

De maneira a esclarecer fatores que podem ter influenciado as colocações na Copa do Mundo 2018, avaliou-se nesta etapa os 4 primeiros lugares do evento, sendo estes: França, Croácia, Bélgica e Inglaterra. Ressalta-se que estes países possuem diferentes papéis no mercado de transferências de jogadores, sendo França e Inglaterra, países de ligas ricas, chamados mercados consumidores, enquanto Croácia e Bélgica, são mercados fazenda.

Para realização desta análise, diferentemente das avaliações anteriores, as quais utilizou-se de uma rede limitada apenas a países presentes no evento, optou-se por uma modelagem de várias redes temporais e abrangentes, possuindo como vértices não apenas os países que se encontram na Copa do Mundo. Ao utilizar este tipo de modelagem é possível estabelecer de maneira integral os vínculos que estes mais países possuem.

Para gerar as redes utilizadas, foi considerado um intervalo de 4 anos. Desta forma, as transações foram agrupadas de modo a sumarizar as transferências realizadas entre uma copa do mundo e outra. De maneira geral, foi considerada essa abordagem para a modelagem da rede, pois, avaliou-se que o ano de copa do mundo em sua primeira parte, é um ano em que seleções estão previamente definidas para defender seu país em competição. Enquanto a segunda parte do ano de copa, após a ocorrência do evento, é um período de reestruturação do time para uma próxima competição caso o time atual não saia vencedor ou não apresente bons resultados. Deste modo, é considerado que o período que irá definir a copa do mundo de 2018, por exemplo, são os anos de 2014 a 2017. Ao final foram geradas 14 redes, sendo que estas representam o período entre as copas do mundo de 1966 à 2018. A Figura 4.4, sumariza de maneira geral a nova modelagem da rede. 


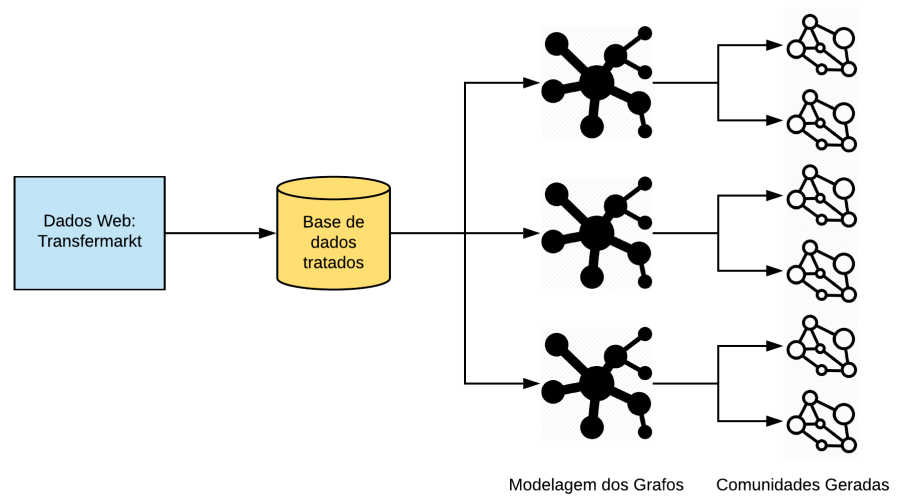

Figura 4. Modelagem da rede para avaliações com os melhores colocados na Copa

Utilizando o conceito anteriormente introduzido de balança comercial, é possível ver por meio da Tabela 14 a balança dos países melhores colocados na Copa do Mundo 2018. Realizando a avaliação da Tabela, vemos que o único país o qual possui uma balança comercial extremamente negativa é a Inglaterra. Já os outros países possuem uma balança comercial positiva, mostrando terem perfis diferentes dentro do mercado de transações de atletas.

\begin{tabular}{|r|r|}
\hline País & Balança Comercial \\
\hline França & $625.317 .000 €$ \\
\hline Croácia & $516.081 .000 €$ \\
\hline Bélgica & $681.330 .000 €$ \\
\hline Inglaterra & $-8.305 .740 .000 €$ \\
\hline
\end{tabular}

Tabela 14. Balança comercial de cada um dos países considerados no estudo

\subsection{França}

A França se sagrou bicampeã da copa do mundo em 2018, sendo seu primeiro título conquistado em 1998. Apesar da França ser um país extremamente rico, estando este presente entre as maiores ligas do mundo [Liu et al. 2016], possuindo atualmente a transação mais cara da história do futebol, o mesmo se beneficia do fato de suas ligações históricas com países africanos anteriormente colonizados por esse para trazer jogadores a baixo custo para suas ligas locais. Vale ressaltar que este o único país entre as 5 grandes ligas (Espanha, Inglaterra, França, Itália e Alemanha) que possui uma balança comercial positiva.

\begin{tabular}{|r|r|}
\hline Maiores Compradores & Maiores Vendedores \\
\hline Inglaterra, Alemanha, Espanha & Brasil, Inglaterra, Portugal \\
\hline
\end{tabular}

Tabela 15. Países que mais fazem negócios com a França

Apesar de grande parte de suas transações relevantes serem com grandes países, como é possível ver na Tabela 15, ao avaliar as comunidades do país é visível resultados divergentes. 
Ao analisar as comunidades as quais a França faz parte é possível ver os parceiros comerciais do mesmo, sendo possível perceber uma grande mudança ao longo dos anos 5 .

Por meio das Tabelas presentes no link, é possível perceber que os parceiros comerciais da França nos primeiros anos são majoritariamente europeus. Contudo, nos últimos anos há uma diversificação deste cenário, sendo ao final encontrados parceiros comerciais de maioria asiática e africana.

O fato é que os parceiros comerciais da França influenciaram diretamente para conquista do bicampeonato já que 15 dos 23 jogadores da seleção possuem dupla nacionalidade, desta forma, percebe-se que a grande tática deste país para possuir um balança comercial positiva mesmo possuindo times tão fortes é a nacionalização e valorização de jogadores de outros continentes.

\subsection{Croácia}

A Croácia, apesar de ser um país formado recentemente(1991), com o fim da Iugoslávia, tem mostrado sua força em competições internacionais, sendo um time em ascensão no futebol. A seleção teve seu melhor desempenho em copas no mundo na Copa do Mundo FIFA 2018, onde conseguiu o segundo lugar, mas anteriormente conquistou o terceiro lugar em 1998.

Apesar do país ter a menor balança comercial entre os países avaliados (considerando apenas a balança comercial positiva), a Croácia possui importantes parceiros comerciais, sendo os principais parceiros a Alemanha e Bélgica.

\begin{tabular}{|r|r|}
\hline Maiores Compradores & Maiores Vendedores \\
\hline Alemanha, Bélgica, Rússia & Alemanha,Bélgica,Brasil \\
\hline
\end{tabular}

Tabela 16. Países que mais fazem negócios com a Croácia

Ao avaliar as comunidades as quais a Croácia faz parte ${ }^{5}$, é possível perceber que grande parte seus parceiros comerciais são países do leste europeu, além dos citados anteriormente. Diferentemente de França e Inglaterra, grande parte dos jogadores desta seleção jogam fora de seus países de origem, estando estes presentes em times de Espanha, Itália e Alemanha. Desta maneira, é possível justificar de certa forma o ótimo desempenho da equipe, já que grande parte de seus atletas atuam em ligas onde há um nível técnico bastante elevado quando comparado ao campeonato nacional croata, capacitando de forma melhor os jogadores de sua seleção.

\subsection{Bélgica}

A Bélgica, assim como Croácia, nunca foi campeã da Copa do Mundo, tendo sua melhor colocação na edição de 2018, onde alcançou o terceiro lugar, anterior a isso sua melhor colocação foi em 1986 na copa do mundo realizada no México onde alcançou o quarto lugar.

\footnotetext{
${ }^{5}$ Tabela com comunidades dos países presente em: https://drive.google.com/open?id=1UkN0LOgxFDgyeA6Iwa9R35AsdM47071

iSys: Revista Brasileira de Sistemas de Informação (iSys: Brazilian Journal of Information Systems) http://seer.unirio.br/index.php/isys/
} 


\begin{tabular}{|r|r|}
\hline Maiores Compradores & Maiores Vendedores \\
\hline Inglaterra,Alemanha,França & França,Alemanha,Croácia \\
\hline
\end{tabular}

Tabela 17. Países que mais fazem negócios com a Bélgica

A Bélgica possui como principais parceiros comerciais países de ligas ricas europeias, como pode-se ver na Tabela 17, e da mesma forma que a Croácia muito do seu bom desempenho se deve ao fato de seus jogadores atuarem em ligas que possuem um nível técnico mais alto, sendo que 12 de seus 23 jogadores atuam na Inglaterra e apenas um atua em um time Belga.

Ao avaliar as comunidades em que o país está presente ${ }^{5}$, percebe-se que um país que realiza muitas transações com a Bélgica é a Holanda, estando este presente em grande parte das comunidades belgas ao longo dos últimos anos analisados.

\subsection{Inglaterra}

A Inglaterra é o país com maior fluxo financeiro no mercado de transações de futebol, tendo movimentado sozinha na temporada 2016/2017 1.3 bilhões de euros [Deloitte 2016]. A grande movimentação realizada pela Inglaterra se deve ao fato de o mesmo possuir diversos times com um poder financeiro extremamente superior a times de outros países. Atualmente, 10 entre os 20 clubes de futebol mais ricos do mundo se encontram presentes na Inglaterra ${ }^{6}$.

Além dos fatos mencionados anteriormente, a Inglaterra é a única seleção entre as analisadas que possui todos os seus jogadores atuando em seu país de origem, o que mostra a força econômica do país ao conseguir manter em sua liga atletas que possuem valor estimado em 915 milhões de euros.

\begin{tabular}{|r|r|}
\hline Maiores Compradores & Maiores Vendedores \\
\hline Espanha,Alemanha,França & França,Espanha,Alemanha \\
\hline
\end{tabular}

Tabela 18. Países que mais fazem negócios com a Inglaterra

Ao avaliar a Tabela 18, percebe-se que os países presentes como maiores parceiros da Inglaterra, são os países de liga rica. Isto auxilia para que a Inglaterra possua a balança comercial mais negativa entre todos os países do mundo, já que a mesma compra de países com a maior média de valor de venda e grande parte de suas transações são de compra.

Analisando as comunidades em que o país se mostra presente ${ }^{5}$, avalia-se que em grande parte seus parceiros comerciais não mudam ao longo dos anos. Desta maneira, seus parceiros em geral são Escócia, País de Gales, Irlanda e Irlanda do Norte. Contudo, destaca-se que o país realiza diversas pequenas transações com países de continentes diferentes, como países da América do Sul, Ásia e África e apesar de suas comunidades serem de certa maneira fechada, o mesmo possui ligações com quase todos os países das redes geradas.

\footnotetext{
${ }^{6}$ https://www.lance.com.br/futebol-internacional/united-real-saiba-clubes-mais-ricos-futebolmundial.html

iSys: Revista Brasileira de Sistemas de Informação (iSys: Brazilian Journal of Information Systems) http://seer.unirio.br/index.php/isys/
} 


\section{Conclusão}

Este trabalho apresentou a análise de uma rede de transferências de jogadores de futebol entre países participantes da copa do mundo. Foram utilizadas técnicas de redes complexas como ranking por algumas medidas de centralidade e detecção de comunidades, sendo feita uma análise pré e pós copa.

Observou-se que esses países são bastante representativos no futebol, abrangendo $50 \%$ das transferências mundiais. essas são bastante frequentes entre a maioria dos países da rede. Pode-se perceber alguns destaques de papéis que alguns países empregam no futebol mundial, por exemplo, se comparamos o Brasil, um país fazenda com a Inglaterra, um país de ligas ricas, pode-se ver dois países bastante diferentes em termos humanos e econômicos. A Inglaterra possui o $16^{\circ}$ IDH do mundo, uma expectativa de vida de 80,8 anos e seus cidadãos estudam em média por 16,3 anos. Enquanto o Brasil é o $79^{\circ}$ de acordo com o IDH, tem expectativa de vida de 74,7 e seus cidadãos estudam em média 15,2. A Inglaterra importa mais matéria prima e exporta produtos industrializados e medicamentos, enquanto o Brasil exporta matéria prima e produtos agrícola e importa produtos industrializados. No Brasil o futebol ainda é uma grande esperança de muitos jovens para mudança de realidade de vida.

As listas top-10 geradas pelas diferentes medidas de centralidade mostraram que os países de ligas ricas são os países mais centrais da rede para qualquer medida de centralidade observada. Contudo, também são encontrados nos rankings países fazenda e países que tem a tradição de realizar a compra de um jogador para vendas futuras, visando principalmente o lucro.

Considerando a estrutura de comunidades, observa-se que os maiores parceiros comerciais estão unidos nos mesmos grupos. No entanto, os países mais centrais estão separados em comunidades isoladas com um parceiro eventual, possivelmente devido ao fato de estes países menores possuírem poucas transações com os demais países da rede.

Foi realizada ainda uma análise pós copa, sendo avaliados os países que tiveram melhores colocações no campeonato. Nas análises realizadas pode-se observar que os parceiros comerciais de um país podem influenciar no desempenho final de sua seleção na Copa do Mundo, sendo esse, um dos fatores que influenciou a conquista do bicampeonato pela França.

Como trabalhos futuros, pretende-se realizar análises de comunidades com métodos que consigam identificar comunidades com sobreposição, pois acredita-se que este tipo de abordagem pode trazer mais informações interessantes. Pretende-se ainda utilizar uma rede com o montante financeiro como peso das arestas para comparação de resultados, além de analisar as redes separadas pelos anos que antecederam a copa e confrontar os resultados com o desempenho das seleções naquele período.

\section{Agradecimentos}

Os autores agradecem às agências de fomento: Capes, CNPq e FAPEMIG.

\section{Referências}

Baade, R. A. and Matheson, V. A. (2004). The quest for the cup: Assessing the economic impact of the world cup. Regional Studies, 38(4):343-354. 
Blondel, V. D., Guillaume, J.-L., Lambiotte, R., and Lefebvre, E. (2008). Fast unfolding of communities in large networks. Journal of Statistical Mechanics: Theory and Experiment, 2008(10):P10008.

Clauset, A., Newman, M. E. J., and Moore, C. (2004). Finding community structure in very large networks. Phys. Rev. E, 70:066111.

Deloitte (June 2016). Annual review of football finance.

Felix, L., Barbosa, C., Vieira, V., and Xavier, C. (2018). Análise do impacto das copas do mundo no mercado de transações de jogadores de futebol e da globalização do futebol utilizando técnicas de redes complexas. In ENIAC 2018 - VII KdMIle ().

Félix, L. G., Barbosa, C. M., Carvalho, I. A., Vieira, V. d. F., and Xavier, C. R. (2018). Uma análise das seleções da copa utilizando uma rede de transferências de jogadores entre pá1ses. In $7^{\circ}$ Brazilian Workshop on Social Network Analysis and Mining (BraSNAM 2018), volume 7. SBC.

Freeman, L. C. (1977). A set of measures of centrality based on betweenness. Sociometry, pages $35-41$.

Freeman, L. C. (1978). Centrality in social networks conceptual clarification. Social Networks, page 215.

Frick, B. (2007). The football players' labor market: Empirical evidence from the major european leagues. Scottish Journal of Political Economy, 54(3):422-446.

González-Badillo, J. J., Pareja-Blanco, F., Rodríguez-Rosell, D., Abad-Herencia, J. L., del Ojo-López, J. J., and Sánchez-Medina, L. (2015). Effects of velocity-based resistance training on young soccer players of different ages. The Journal of Strength \& Conditioning Research, 29(5):1329-1338.

Iandoli, R. (2018). Quer ficar mais caro? marque gols em uma copa do mundo.

Jarvie, G. (2003). Sport, racism and british society: A sociological study of england's elite male afro/caribbean soccer and rugby union players. In Sport, racism and ethnicity, pages 79-102. Routledge.

Lees, A., Asai, T., Andersen, T. B., Nunome, H., and Sterzing, T. (2010). The biomechanics of kicking in soccer: A review. Journal of sports sciences, 28(8):805-817.

Liebig, J., Rhein, A. V., Kastner, C., Apel, S., Dorre, J., and Lengauer, C. (2012). Largescale variability-aware type checking and dataflow analysis.

Liu, X. F., Liu, Y.-L., Lu, X.-H., Wang, Q.-X., and Wang, T.-X. (2016). The anatomy of the global football player transfer network: Club functionalities versus network properties. PloS one, 11(6):e0156504.

Magee, J. and Sugden, J. (2002). "the world at their feet" professional football and international labor migration. Journal of sport and social issues, 26(4):421-437.

Martin, W. (2018). From 950, 000to220 million: The most valuable player for every team at the 2018 world cup.

Newman, M. E. J. (2006). Finding community structure in networks using the eigenvectors of matrices. Phys. Rev. E, 74:036104. 
Newman, M. E. J. and Girvan, M. (2004). Finding and evaluating community structure in networks. Phys. Rev. E, 69:026113.

Osgnach, C., Poser, S., Bernardini, R., Rinaldo, R., and Di Prampero, P. E. (2010). Energy cost and metabolic power in elite soccer: a new match analysis approach. Med Sci Sports Exerc, 42(1):170-178.

Page, L., Brin, S., Motwani, R., and Winograd, T. (1999). The pagerank citation ranking: Bringing order to the web. Technical Report 1999-66, Stanford InfoLab. Previous number $=$ SIDL-WP-1999-0120.

Palacios-Huerta, I. (2004). Structural changes during a century of the world's most popular sport. Statistical Methods and Applications, 13(2):241-258.

Redhead, S. (2002). Post-fandom and the millennial blues: The transformation of soccer culture. Routledge.

Taylor, I. (2014). On the sports violence question: soccer hooliganism revisited. Sport, Culture and Ideology (RLE Sports Studies), page 152. 